\title{
Severe Low Cardiac Output Following Pericardiectomy- Bird in Cage Phenomenon
}

\author{
Mridu Paban Nath ${ }^{1 *}$, Malavika Barman² and Rajib Kr Bhattacharrya ${ }^{3}$ \\ ${ }^{1}$ Assistant Professor, Department of Anesthesiology \& Critical Care, Gauhati Medical College Hospital, Assam, India \\ ${ }^{2}$ Assistant Professor, Department of Biochemistry, Tezpur Medical College Hospital, Assam, India \\ ${ }^{3}$ Professor \& Head, Department of Anesthesiology \& Critical Care, FAA Medical College Hospital, Assam, India
}

A 28 year old boy was referred from a private hospital for evaluation of constrictive pericarditis. He was diagnosed for the same about 4 years back with history of worsening shortness of breath and fatigue. At the time of presentation, patient required supplemental Oxygen and was New York Heart Association Class-IV heart failure. Physical examination revealed distension of jugular veins with significant ascites \& hepatomegaly. Bilateral pedal edema was absent; however patient was on long term therapy with loop diuretics. About 1 litre of abdominal paracentesis was done to relieve tense ascites. A chest X-ray revealed pericardial calcification which was confirmed by computed tomography scan showing thickened pericardium with calcification with mild bilateral pleural effusion and congestion of liver. Preoperative echocardiography showed left ventricular ejection fraction between $40 \%$ and $45 \%$ with thickened pericardium. He had past history of completion of full course of antitubecular treatment for the same in recent past. Routine biochemical tests within normal limit and an elective pericardiectomy was planned through lateral thoracotomy approach under general anesthesia.

Patient was transferred to the operation theatre with supplemental Oxygen having peripheral saturation (Spo2) 98-99\%. Right radial artery catheterization was done under local anesthesia showing blood pressure of $130 / 80 \mathrm{~mm} \mathrm{Hg}$ and heart rate $115 / \mathrm{min}$. Patient was induced with Fentanyl, Etomidate and intubated after muscle relaxation with Rocuronium. Anesthesia was maintained with Oxygen and air (50:50) with Sevoflurane. Intraoperative vitals were maintained with blood pressure ranging 110-130/70-90 $\mathrm{mm} \mathrm{Hg}$, heart rate 110-140/min, SpO2 98-100\% and EtCO2 30-40 mm Hg. Through left lateral thoracotomy approach, pericardiectomy was preceded. After removing about $5 \mathrm{~cm}$ $\mathrm{X} 4 \mathrm{~cm}$ portion of thickened calcified pericardium, ventricles were visualized contracting poorly and the right atrium was distended with no contraction at all. The blood pressure suddenly dropped to $40 / 20 \mathrm{~mm} \mathrm{Hg}$ with EtCO2 to $10 \mathrm{~mm} \mathrm{Hg}$. Fluid bolus with 300 $\mathrm{ml}$ hydroxyl ethyl starch (130/0.4) via large bore veins revealed no significant improvement in blood pressure and intracardiac massage was started with infusion of high doses of Dobutamine, Adrenaline and Noradrenaline and ventilation continued with 100\% Oxygen. Urgently trans-esophageal echocardiography was done which showed severe reduction of systolic function with ejection fraction dropped to less than $20 \%$ without any valvular incompetence. Surgery temporarily stopped and resuscitation continued. Despite 20 minutes of heroic efforts, the refractory heart failure progressed to death.

Low cardiac output syndrome (LCOS) after pericardiectomy seen in a small but not insignificant portion of patients with constrictive pericarditis, regardless of the operative approach or the extent of pericardial resection [1]. Despite extensive pericardiectomy, there always have some early deaths due to LCOS and this is because outcome is related not only to the extent of surgery, but to myocardial involvement. Autopsy findings indicate that myocardial fibrosis and atrophy may result from chronic constrictive pericarditis [1-3]. LCOS can also be caused by changes in cardiac architecture resulting from long periods of myocardial compression contributing to remodelling of the ventricles and to greater involvement of the myocardium in patients who have undergone long periods of symptomatic pericardial constriction, as in our patient with a history of 4 years of symptoms.

MacCaughan et al. [4] have described haemodynamic abnormalities after pericardiectomy in the largest series available (231 patients). The investigators noted a $28 \%$ incidence of LCOS postoperatively in their patients, with many of the perioperative deaths occurring in this low cardiac output group. Some patients also develop unexplained abrupt decrease in left ventricular ejection fraction noted in early postoperative periods which gradually improved over the next 4 weeks [5].

LCOS can be considered a form of acute heart failure (AHF). In the same way that AHF produces high mortality in non-surgical patients, [6] LCOS is a major cause of perioperative death in patients undergoing cardiac surgery $[7,8]$. LCOS is, however, a peculiar form of AHF as it differs from the latter in etiology, prognosis, and treatment, all of which are influenced by the combination of surgery and anesthesia. In both AHF and LCOS, there is clearly an underlying myocardial dysfunction, though the term "AHF" is too broad and all-embracing. In the surgical context, "low output syndrome" is preferred, as it more precisely defines the patient's clinical condition. All surgical patients with a cardiac index of $<2.2 \mathrm{~L} / \mathrm{min} / \mathrm{m}^{2}$ and without hypovolemia have low output syndrome $[7,8]$.

Although the general principles for treating AHF apply in the case of LCOS, there are nevertheless some clear differences. Adequate oxygenation should be ensured by using mechanical ventilation and the usual anesthetic care. In surgical patients with low output, hypertension is not present and vasodilatation should be approached with caution in patients who are already usually vasodilated. According to the European Society of Cardiology guidelines for the treatment of AHF, levosimendan is the inotropic drug for which most evidence is available [9]. The same level of evidence is not available regarding the drug's use in surgical patients. Published series have usually included only a small number of patients, have been performed in only 1 centre, and have not analyzed survival [10]. Levosimendan was introduced into clinical practice based on favourable results from the LIDO [11] and

*Corresponding author: Mridu Paban Nath MD (Anaesthesiology), Assistant Professor \& I/C Cardiac Anaesthesia, Department of Anaesthesiology \& Critical Care, Gauhati Medical College Hospital, Guwahati, Assam, India, Tel: 09957630954;09207308919; 09085311194; 09871184308; E-Mail: drmridupaban@yahoo.com

Received February 11, 2014; Accepted April 26, 2014; Published April 28, 2014

Citation: Nath MP, Barman M, Bhattacharrya RK (2014) Severe Low Cardiac Output Following Pericardiectomy- Bird in Cage Phenomenon. J Vasc Med Surg 2: 135. doi: 10.4172/2329-6925.1000135

Copyright: $\odot 2014$ Nath MP, et al. This is an open-access article distributed under the terms of the Creative Commons Attribution License, which permits unrestricted use, distribution, and reproduction in any medium, provided the original author and source are credited. 
Citation: Nath MP, Barman M, Bhattacharrya RK (2014) Severe Low Cardiac Output Following Pericardiectomy- Bird in Cage Phenomenon. J Vasc Med Surg 2: 135. doi: 10.4172/2329-6925.1000135

RUSLAND [12] studies and although the results from the SURVIVE [13] study have not confirmed the tendency, its use in patients with worsening heart failure is based on improvements in survival.

This phenomenon of LCOS after pericardiectomy in constrictive pericarditis can be correlated with that of "bird in cage phenomenon", where after keeping a bird for few years in a cage, forgets to fly, if allowed to do so. Like this phenomenon, after long periods of pericardial constriction, upon releasing the same, heart fails to pump which ultimately leads to severe LCOS. So, while dealing with such type of patients, proper anaesthetic care with all emergency drugs should be kept ready to counteract such catastrophe.

\section{References}

1. De Valeria PA, Baumgartner WA, Casale AS, Greene PS, Cameron DE, et al. (1991) Current indications, risks, and outcome after pericardiectomy. Ann Thorac Surg 52: 219-224.

2. Dines DE, Edwards JE, Burchell HB (1958) Myocardial atrophy in constrictive pericarditis. Proc Staff Meet Mayo Clin 33: 93-99.

3. Roberts JT, Beck CS (1941) The effect of chronic cardiac compression on the size of the heart muscle fibres. Am Heart J 22: 314-319.

4. McCaughan BC, Schaff HV, Piehler JM, Danielson GK, Orszulak TA, et al. (1985) Early and late results of pericardiectomy for constrictive pericarditis. J Thorac Cardiovasc Surg 89: 340-350.

5. Schofield RS, Shoemaker SB, Ryerson EG, Cooper GR, Spotnitz WD (2004) Left ventricular dysfunction after pericardiectomy for constrictive pericarditis. Ann Thorac Surg 77: 1449-1451.
6. Delgado JF (2006) Levosimendan in acute heart failure: past, present and future [editorial]. Rev Esp Cardiol 59: 309-312.

7. Álvarez J, Bouzada M, Fernández AL, Cauezo V, Taboada M, et al. (2006) Hemodynamic effects of levosimendan compared with dobutamine in patients with low cardiac output after cardiac surgery. Rev Esp Cardiol 59: 338-345.

8. Levin RL, Degrange MA, Porcile R, Salvagio F, Blanco N, et al. (2008) The calcium sensitizer levosimendan gives superior results to dobutamine in postoperative low cardiac output syndrome. Rev Esp Cardiol 61: 471-479.

9. Nieminen MS, Böhm M, Cowie MR, Drexler H, Filippatos GS, et al. (2005) Executive summary of the guidelines on the diagnosis and treatment of acute heart failure: The Task Force on Acute Heart Failure of the European Society of Cardiology. Eur Heart J 26: 384-416.

10. Raja SG, Rayen B (2006) Levosimendan in cardiac surgery: Current best available evidence. Ann Thorac Surg 81: 1536-1546.

11. Follath F, Cleland JG, Just H, Papp JG, Scholz H, et al. (2002) Efficacy and safety of intravenous levosimendan compared with dobutamine in severe lowoutput heart failure (the LIDO study): a randomised double-blind trial. Lancet 360: 196-202.

12. Moiseyev VS, Poder P, Andrejevs N, Ruda MY, Golikov AP, et al. (2002) Safety and efficacy of a novel calcium sensitizer, levosimendan, in patients with left ventricular failure due to an acute myocardial infarction. A randomized, placebocontrolled, double-blind study (RUSSLAN). Eur Heart J 23: 1422-1432.

13. Mebazaa A, Nieminen MS, Packer M, Cohen-Solal A, Kleber FX, et al. (2007) Levosimendan vs dobutamine for patients with acute decompensated heart failure: the SURVIVE Randomized Trial. JAMA 97: 1883-1891. 